\title{
Clinicolopathological, Cytogenetic, and Radiographical Analysis of Waldenstrom Macroglobulinemia in Japan: Unique Disease Manifestation
}

\author{
Naohiro Sekiguchi $^{{ }^{*}}$, Naoki Takezako ${ }^{1}$, Miyuki Wagatsuma ${ }^{2}$, Chen A. Kunihiro ${ }^{1}$, Akihisa Nagata ${ }^{1}$, \\ Ichiro Fukuda $^{3}$, Satoshi Noto ${ }^{1}$, Ikuo Saito ${ }^{4}$, Kazuaki Yamada ${ }^{2}$, Akiyoshi Miwa ${ }^{5}$ \\ ${ }^{1}$ Division of Hematology, National Hospital Organization Disaster Medical Center, Tokyo, Japan; ${ }^{2}$ Division of Pathology, National \\ Hospital Organization Disaster Medical Center, Tokyo, Japan; ${ }^{3}$ Division of Radiology, National Hospital Organization Disaster \\ Medical Center, Tokyo, Japan; ${ }^{4}$ Division of Pathology, National Hospital Organization Sagamihara Hospital, Sagamihara, Japan; \\ ${ }^{5}$ Hematology Division, National Center for Global Health and Medicine, Tokyo, Japan. \\ Email: "nao26@aol.com
}

Received September $15^{\text {th }}, 2012$; revised October $17^{\text {th }}, 2012$; accepted October $28^{\text {th }}, 2012$

\begin{abstract}
Waldenström macroglobulinemia (WM) is a rare lymphoid malignancy. Many studies, including clinicopathological, cytogenetic, gene expression profile, and therapy studies have been reported from the US and Europe, although only a few reports are available from East Asia, including Japan. To further clarify the clinicopathological, radiological, and cytogenetic features of WM in Japan, we performed a retrospective analysis of WM in our institute between March 2007 and January 2012. Clinical data, laboratory data, the results of flow cytometric analysis (FCM), and chromosomal abnormalities were analyzed, and a radiological review was performed. The treatment regimen, response, and survival were also estimated. Six patients were enrolled in this study. The median age was 71 years. All patients were symptomatic, 3 had hyperviscosity syndrome, 1 had bone lesions, and 1 had an extra-medullary mass. FCM data showed that all patients were positive for CD38, while 2 were positive for CD56. Four had chromosomal abnormalities including some abnormalities also reported in myeloma. On radiological review, four showed diffuse invasion of the retro-peritoneum. Five patients received treatment, 4 of which achieved a response. At a median follow-up of 527 days, 4 were alive and 2 died because of disease progression. The present study revealed that WM in Japan might be heterogeneous and have a unique disease manifestation. Invasion sites other than bone marrow were very common, and the results of clinical, FCM, and cytogenetic studies revealed that WM in Japanese cases might have manifestations of both myeloma and B-cell lymphoma.
\end{abstract}

Keywords: Lymphoplasmacytic Lymphoma; Woldenström Macroglobulinemia; Lymphadenopathy; Flow Cytometry; Pathology; Cytogenetics; Japan

\section{Introduction}

Woldenström macroglobulinemia (WM) and lymphoplasmacytic lymphoma (LPL) are defined as neoplasms of small B-cell lymphocytes and have been recognized as distinct disease entities in the World Health Organization (WHO) Classification [1]. WM usually shows monoclonal gammopathy of immunoglobulin (Ig) $\mathrm{M}$, although serum IgG and $\operatorname{IgA}$ levels are normal or still low. WM involves the bone marrow and sometimes the peripheral blood, liver, spleen, and lymph nodes, and it has been recognized as indolent B-cell lymphoma. Compared to multiple myeloma, the incidence of bone lesion, renal insufficiency, and extramedulally mass is rare. Sometimes WM is complicated with B symptoms, hypervis-

"Corresponding author. cosity syndrome, cryoglobulinemia, and cold agglutinin disease (CAD), however the clinical course is relatively indolent after successful induction therapies [1-3]. The incidence of WM has been reported to be very low, at about $1.2 \%$ and $0.7 \%$ of non-Hodgkin's lymphoma in Western countries [4] and Japan [5], respectively. Many studies, including clinicopathological, cytogenetic, gene expression profile, and therapy studies have been reported from the US and European countries [2-4,6-22], although only a few reports are available from East Asia, including Japan [23-27]. Regarding the initial therapy, many promising agents, including rituximab, bortezomib, a purine analogue, bendamsutine, and combination chemotherapies have been reported [6,9-11], although standard initial therapy has not been established.

To further clarify the features of patients with WM in 
Japan, we analyzed the clinical, radiological, pathological, and cytogenetic features of 6 patients who were diagnosed and treated in our institution. To the best of our knowledge, this is the largest report in Japan.

\section{Patients and Methods}

\subsection{Patients}

Six patients who were diagnosed with WM and treated at the National Hospital Organization Disaster Medical Center between March 2007 and January 2012 were enrolled in this study. The institutional review board of our hospital approved this study. The diagnostic criteria of WM in the present study were generally according to the WHO classification. Additionally, the ratio of lymphoplasmacytic to plasma cells was more than the $10 \%$ in bone marrow aspirates required in the present criteria. Clinical data were obtained from the medical charts, including the age, sex, chief complaint, B symptoms, performance status (PS), white blood cell (WBC) count, percentage of neutrophils, percentage of lymphocytes, hemoglobin $(\mathrm{Hb})$ level, platelet (plt) count, serum beta 2-microglobulin (beta 2-MG) level, serum total protein, serum albumin (alb), serum lactate dehydrogenase (LDH), serum creatinine clearance, serum compensated $\mathrm{Ca}$, serum IgM, serum IgG, serum IgA, prothrombin time, fibrinogen, clyoglobulinemia, other complications, and treatment. PS was determined according to the Eastern Cooperative Oncology Group scale [28].

\subsection{Radiological Review}

Radiological review was performed by computed tomography $(\mathrm{CT})$ in all cases and by magnetic resonance imaging (MRI) in some cases by a radiologist.

\subsection{Flow Cytometric Analysis and Histopathological Examination}

Two-color flow cytometric analysis (FCM) was performed using bone marrow aspirates. The surface antigens for CD10, 19, 20, 38, 56, kappa, and lambda were essentially evaluated in CD45 or CD38 strong-positive fractions. These fractions were estimated as positive for a particular antigen if more than $20 \%$ of the cells expressed the antigen. CD5-positive cases were excluded in the present study. In some cases, we applied hematoxylineosin staining of sections of bone marrow biopsy specimens, and lymphoma cell-involved tissues. In addition to histopathology, paraffin-embedded sections were subjected to immunohistochemical staining (IHC) by the standard avidin-biotin method using monoclonal antiCD45 (PD7/26/16.2B11; Nichirei Bioscience Inc., Tokyo, Japan), anti-CD20 (L26; Roche Diagnostics K.K., Tokyo,
Japan), anti-CD79a (JCB117; Nichirei Bioscience Inc.), anti-CD138 (B-A38; Nichirei Bioscience Inc.), anti-IgM (R1/69; Nichirei Bioscience Inc.), anti-kappa (L1C1; Nichirei Bioscience Inc.), anti-lambda (HP6054; Nichirei Bioscience Inc.), and anti-Ki-67 (MIB-1; Dako, Glostrup, Denmark).

\subsection{Cytogenetic Analyses}

Conventional cytogenetic analysis of bone marrow cells was performed with the G-banding method. In some cases, we performed fluorescence in situ hybridization (FISH) analysis to detect major cytogenetic abnormalities regarding lymphoma and myeloma. The probes included del13q (Vysis 13q34 SpectrumGreen FISH probe kit), IgH/Bcl1 (Vysis IgH/CCND1 XT DF FISH Probe kit), IgH/Bcl2 (Vysis LSI IGH/BCL2 Dural Color, Dual Fusion Translocation Probe), IgH/FGFR3 (Vysis IgH/ FGFR3 DF FISH Probe kit), Myc/IgH (Vysis IGH/ MYC/CEP 8 Tri-Color DF FISH Probe Kit), del17p (Vysis TP53/CEP17 FISH Probe kit), and IgH/MAF1 (Vysis IgH/MAF DF FISH Probe kit). All probe sets were from Abbott Laboratories (Abbot Park, IL, USA). FISH procedures were performed according to the $\mathrm{Ab}$ bott FISH technology protocol [29].

\subsection{Assessment of Response and Survival}

The response was defined according to the Updated Response Criteria adopted by the 6th International Workshop on WM [30]. Briefly, complete response (CR) was defined as showing the resolution of all symptoms, normalization of serum IgM levels with the complete disappearance of IgM paraprotein by immunofixation, no evidence of disease by bone marrow examination, and the resolution of any adenopathy or splenomegaly. Patients achieving a very good partial response (VGPR), partial response (PR), and a minor response (MR) were defined as achieving $>90,50 \%-90 \%$, and $25 \%-50 \%$ reduction in serum IgM levels, respectively. Patients with stable disease (SD) were defined as showing $<25 \%$ change in serum IgM, in the absence of new or increasing adenopathy or splenomegaly and/or other progressive signs or symptoms of WM. Progressive disease was defined as occurring when $>25 \%$ increase in serum IgM occurred from the lowest attained response value or progression of clinically significant disease-related symptoms. All the symptomatic cases were scored using the International Scoring System for WM (IPSWM) [31]. Adverse characteristics were advanced age ( $>65$ years), $\mathrm{Hb} \leq 11.5$ $\mathrm{g} / \mathrm{dL}$, plt count $\leq 100 \times 10^{9} / \mathrm{L}$, beta 2 -microglobulin $>3$ $\mathrm{mg} / \mathrm{L}$, and serum monoclonal protein concentration $>7.0$ $\mathrm{g} / \mathrm{dL}$. Low-risk patients presented with no or 1 of the adverse characteristics and advanced age, intermediate- 
risk patients with 2 adverse characteristics or only advanced age, and high-risk patients with more than 2 adverse characteristics. The follow-up duration was calculated between the diagnoses and last follow-up. Survival was also analyzed at the date of the last follow-up.

\subsection{Initial Treatments}

Five patients with symptomatic WM received chemotherapy. As an initial therapy, 3 patients received RCHOP (rituximab, cyclophosphamide [CPA], doxorubicin, vincristine, and prednisolone)-like regimens. One received CPA and dexamethasone, and 1 received cladribine. No patients received radiotherapy.

\section{Results}

\subsection{Clinical Features}

The clinical characteristics of the 6 patients at diagnosis are shown in Table 1. The median age was 71 years (range: 55 - 83 years). Four patients were male and 2 were female. Two showed an excess of WBC, 5 had anemia, 1 had thrombocytopenia, and 3 had coagulation abnormalities including prothrombin time and the serum fibrinogen level. The exact serum Ig level was not obtained in case 4 because of hypergammopathy, although serum protein electrophoresis and immunoelectrophoresis revealed monoclonal hypergammopathy of IgM (data not shown). Elevated LDH was recognized in 2 cases. All patients were defined as symptomatic, 4 out of 6 had B symptoms, and 1 had CAD. Five out of 6 symptomatic patients had a PS score $>1: 3$ had hyperviscosity syndrome, 1 had bone lesions, and 1 had an extra-medullary mass. One had renal insufficiency because of CAD. Three were scored as intermediate, and 3 were high risk based on the IPSWM.

\subsection{Radiological Review}

On radiological review, all patients had hepatosplenomegaly except for one with cirrhosis of the liver. Four out of the 6 patients had tumor infiltration. Four cases involved the para-aorta, and 2 had retro-cruel involvement. Invasion of the common iliac, extra iliac, and inguinal regions, and post kidney was recognized in 1 case. The pattern of tumor invasion was appropriate to examine the soft tissue mass rather than lymphadenopathy in the retro-peritoneum (Figure 1(a)). Case 3 had a compression fracture in lumbar vertebrae on MRI (Figure 1(b)).

\subsection{Flow Cytometric, Pathological, and Cytogenetic Analyses}

All patients had FCM data available, shown in Table 2,

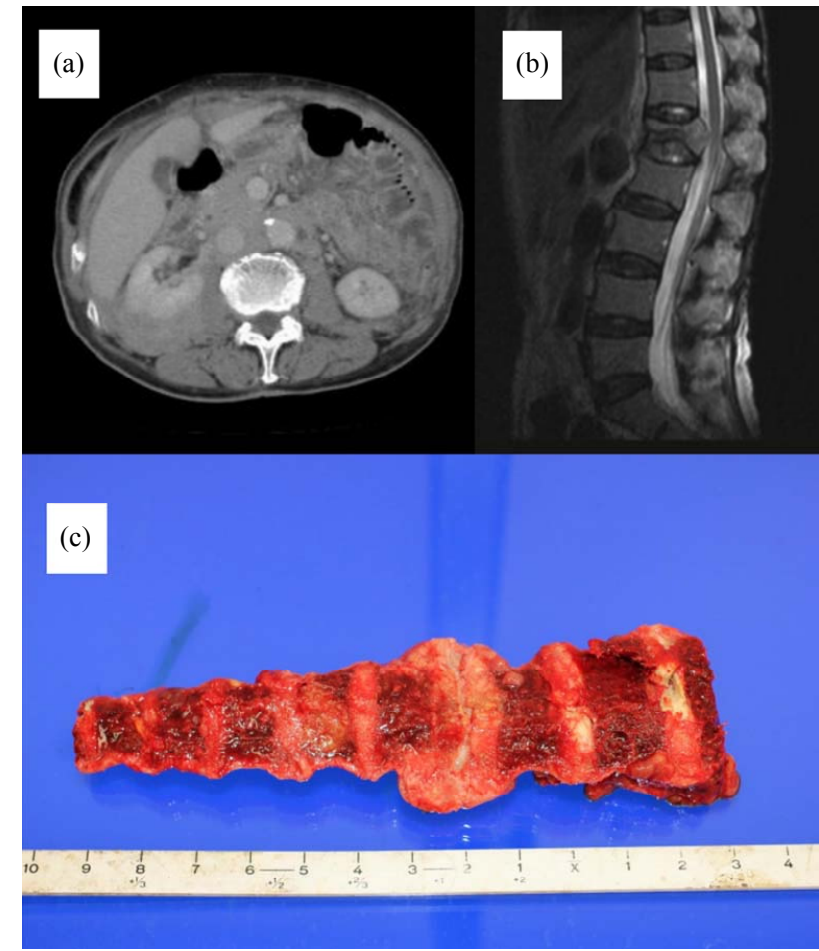

Figure 1. (a) Computed tomography scan of case 4. Diffuse soft tissue invasion of the retro-peritoneum was identified; (b) Magnetic resonance imaging of case 3 . Compression fracture of lumbar vertebrae; (c) Case 4 had a thoracic extramedullary mass based on an autopsied specimen.

and all were positive for $45,19,20$, and CD38, while 2 were positive for CD56. On the other hand, all cases were negative for $\mathrm{CD} 10$.

IHC study results were available in 4 cases (Table 2). Three patients had results available for IHC from bone marrow biopsied specimens, and all were positive for CD45, CD20, CD79a, and CD138. Case 4 underwent an autopsy. The patients had an extramedullary mass in the thoracic vertebrae (Figure 2(a)) and diffuse infiltration in the post-peritoneum. IHC staining of the extramedullary mass and post-peritoneum specimen showed that the tumor cells were positive for CD45, CD79a (data not shown), CD20, CD138, IgM, lambda, and MIB-1 (Figures 2(b)-(h)). The MIB-1 index was around $20 \%$ of neoplastic cells, with staining mainly in the large nuclei.

Cytogenetic study results are shown in Table 3. Four had chromosomal abnormalities and 3 showed some abnormalities by the G-band method. Abnormalities of add (8)(p11.2) were detected in case 5 and add (3)(p21), add (6)(q13) in case 4. In case 1, complex abnormalities were recognized, including add $(6)(q 13) \times 2$. FISH analysis showed no typical abnormalities. On the other hand, additional chromosomes of 8 and 17 were recognized in case 1 , because the probe set had the centromere of chromosome 8 in the Myc/IgH probe set and that of 17 in 
Table 1. Clinical characteristics, initial treatment, response, and outcome of LPL.

\begin{tabular}{|c|c|c|c|c|c|c|c|c|c|c|c|}
\hline \multicolumn{2}{|c|}{ Case } & \multicolumn{2}{|l|}{1} & \multicolumn{2}{|l|}{2} & 3 & 4 & \multicolumn{2}{|r|}{5} & \multicolumn{2}{|r|}{6} \\
\hline \multicolumn{2}{|c|}{ Sex } & \multicolumn{2}{|l|}{ M } & \multicolumn{2}{|l|}{ M } & $\mathrm{F}$ & M & \multicolumn{2}{|r|}{$\mathrm{F}$} & \multicolumn{2}{|r|}{ M } \\
\hline \multicolumn{2}{|c|}{ Age } & \multicolumn{2}{|c|}{58} & \multicolumn{2}{|l|}{70} & 76 & 83 & & 72 & \multicolumn{2}{|r|}{55} \\
\hline \multicolumn{2}{|c|}{ Chief complaint } & \multicolumn{2}{|c|}{ Anemia, fatigue } & \multicolumn{2}{|c|}{ Anemia, fatigue } & $\begin{array}{l}\text { Compression } \\
\text { fracture }\end{array}$ & $\begin{array}{c}\text { Anemia, Nasal } \\
\text { discharge }\end{array}$ & & Headache & \multicolumn{2}{|c|}{ Syncope } \\
\hline \multicolumn{2}{|c|}{ B symptom } & \multicolumn{2}{|c|}{$(+)$} & $(-)$ & & $(+)$ & $(+)$ & & $(-)$ & & $(+)$ \\
\hline & & 2 & & 2 & & 3 & 2 & & 1 & & 1 \\
\hline WBC & $\left.10^{9} / \mathrm{L}\right)$ & 6.5 & & 14 & & 4.8 & 3.2 & & 4.3 & & 30.9 \\
\hline & & 67 & & 91 & & 61 & 71 & & 58 & & 35 \\
\hline & & 17 & & 4 & & 25 & 16 & & 32 & & 65 \\
\hline $\mathrm{Hb}$ & & 8.6 & & 4.0 & & 7.9 & 7.6 & & 12.6 & & 3.5 \\
\hline Plt ( & $\left.9^{9} / \mathrm{L}\right)$ & 468 & & 275 & & 206 & 186 & & 225 & & 15 \\
\hline Beta 2-I & $(\mathrm{mg} / \mathrm{L})$ & 6.7 & & 2.8 & & 3 & 4.1 & & 1.6 & & 6.9 \\
\hline ТP & & 7.3 & & 5.8 & & 79 & 10.3 & & 8.3 & & 11.3 \\
\hline $\mathrm{Alb}$ & (dL) & 2.3 & & 3 & & 3.1 & 2.1 & & 4.4 & & 3.7 \\
\hline LDH & $\mathrm{U} / \mathrm{L})$ & 160 & & 785 & & 138 & 77 & & 160 & & 299 \\
\hline CCR & $/ \min )$ & 78 & & 29 & & 109 & 78 & & 55 & & 8.84 \\
\hline $\mathrm{cCa}$ & /dL) & 10. & & 9.3 & & 9.5 & 11.1 & & 9.7 & & 10.9 \\
\hline $\operatorname{IgM}$ & /dL) & 183 & & 697 & & 1529 & 317 & & 2320 & & 246 \\
\hline $\operatorname{IgG}$ & $/ \mathrm{dL})$ & 734 & & 533 & & 1307 & 330 & & 965 & & 781 \\
\hline $\operatorname{IgA}$ & $/ \mathrm{dL})$ & 56 & & 31 & & 83 & 55 & & 113 & & 127 \\
\hline & & 64 & & 117 & & 7.3 & 61 & & 91 & & 69 \\
\hline Fib & $/ \mathrm{dL})$ & 593 & & 145 & & 486 & 143 & & 220 & & 186 \\
\hline & & I & & I & & $\mathrm{H}$ & $\mathrm{H}$ & & I & & $\mathrm{H}$ \\
\hline Cryo & bulin & $(-)$ & & $(-)$ & & $(-)$ & $(-)$ & & N.A & & $(+)$ \\
\hline Other co & lications & Hypervis & sity & CAD & & Bone lesion & Extramedullary mass & & perviscosity & $\begin{array}{l}\text { Hype } \\
\text { HCV in }\end{array}$ & $\begin{array}{l}\text { viscosity, } \\
\text { fection, LC }\end{array}$ \\
\hline Tre & & $\mathrm{R}-\mathrm{CHO}$ & & $\mathrm{R}-\mathrm{CHOP}$ & & $\mathrm{R}-\mathrm{CHOP} \times 6$ & CPM-D $\times 1$ & & adribine $\times 4$ & & $(-)$ \\
\hline Res & & PR & & VGPI & & PR & PD & & PR & & \\
\hline & & $(+)$ & & $(+)$ & & $(+)$ & $(-)$ & & $(+)$ & & $(-)$ \\
\hline $\begin{array}{l}\text { LPL: lymp } \\
\text { 2-MG: bet } \\
\text { PT: prothr } \\
\text { HD: hemo } \\
\text { partial res }\end{array}$ & $\begin{array}{l}\text { plasmacyt } \\
\text {-microglol } \\
\text { bin time; } \\
\text { lysis; HCX } \\
\text { se; VGPR }\end{array}$ & $\begin{array}{l}\text { lymphom } \\
\text { alin; TP: to } \\
\text { ib: fibrinog } \\
\text { hepatitis C } \\
\text { very good }\end{array}$ & $\begin{array}{l}\text { : perf } \\
\text { rotein } \\
\text { PSWI } \\
\text { is; LC } \\
\text { al resp }\end{array}$ & $\begin{array}{l}\text { rmance sta } \\
\text { lb albumin; } \\
\text { : Internatio } \\
\text { liver chirro } \\
\text { nse; PD: pr }\end{array}$ & $\begin{array}{l}\text { WBC: w } \\
\text { H: lactat } \\
\text { Prognost } \\
\text { CPM: cy } \\
\text { essive dis }\end{array}$ & $\begin{array}{l}\text { hite blood cell; } \\
\text { dehydrogenase } \\
\text { ic Scoring Syste } \\
\text { clophosphamide } \\
\text { ease. }\end{array}$ & $\begin{array}{l}\text { eu: neutrophil; Lym: lyn } \\
\text { CCR: creatinine clearanc } \\
\text { for Waldenstrom Macr } \\
\text { R-CHOP: rituximab; CP }\end{array}$ & $\begin{array}{l}\text { mphocyt } \\
\text { ice; cCa: } \\
\text { roglobul } \\
\text { PM, dox }\end{array}$ & $\begin{array}{l}\text { yte; Hb: hem } \\
\text { a: compensate } \\
\text { linemia; CAI } \\
\text { xorubicin, vin }\end{array}$ & $\begin{array}{l}\text { lobin; Plt: } \\
\text { Ca; Ig: im } \\
\text { cold aggl } \\
\text { istine, pre }\end{array}$ & $\begin{array}{l}\text { platelet; Beta } \\
\text { nunoglobulin } \\
\text { tinin disease; } \\
\text { lnisolone; PR }\end{array}$ \\
\hline Case & & & & & & & & & IF & & \\
\hline & CD45 & CD10 & CD19 & $\mathrm{CD} 20$ & $\mathrm{CD} 38$ & CD56 & $\lambda$ & CD45 & $\mathrm{CD} 20$ & CD79a & CD138 \\
\hline 1 & $(+)$ & $(-)$ & $(+)$ & $(+)$ & $(+)$ & $(+)$ & $(+)$ & $(+)$ & $(+)$ & $(+)$ & $(+)$ \\
\hline 2 & $(+)$ & $(-)$ & $(+)$ & $(+)$ & $(+)$ & $(-)$ & $(+)$ & $(+)$ & $(+)$ & $(+)$ & $(+)$ \\
\hline 3 & $(+)$ & $(-)$ & $(+)$ & $(+)$ & $(+)$ & $(-)$ & $(+)$ & $(+)$ & $(+)$ & $(+)$ & $(+)$ \\
\hline 4 & $(+)$ & $(-)$ & $(+)$ & $(+)$ & $(+)$ & $(-)$ & $(+)$ & $(+)$ & $(+)$ & $(+)$ & $(+)$ \\
\hline 5 & $(+)$ & $(-)$ & $(+)$ & $(+)$ & $(+)$ & $(+)$ & $(+)$ & N.A. & N.A. & N.A. & N.A. \\
\hline 6 & $(+)$ & $(-)$ & $(+)$ & $(+)$ & $(+)$ & $(-)$ & $(+)$ & N.A. & N.A. & N.A. & N.A. \\
\hline
\end{tabular}

FCM: flow cytometric analysis; IHC: immunohistochemistry. 
Table 3. Results of fluorescense in situ hybridization and G-band.

\begin{tabular}{|c|c|c|c|c|c|c|c|c|}
\hline \multicolumn{9}{|c|}{ Results of FISH analysis } \\
\hline Case & G-band & $13 q$ del & $\mathrm{Bcl1} / \mathrm{IgH}$ & $\mathrm{Bcl} 2 / \operatorname{IgH}$ & FGFR3/IgH & $\mathrm{MYC} / \mathrm{C} 8 / \mathrm{IgH}$ & $\mathrm{MAF} / \mathrm{IgH}$ & $\mathrm{p} 53 / \mathrm{C} 17$ \\
\hline 1 & ${ }^{*} 1$ & $(-)$ & $(-) \mathrm{B} 3 / \mathrm{H} 3$ & $(-)$ & $(-) \mathrm{F} 3 / \mathrm{H} 3$ & (-) $\mathrm{M} 4 / \mathrm{C} 4 / \mathrm{H} 3$ & N.A. & (-) $17 \mathrm{p} 3 / \mathrm{C} 3$ \\
\hline 2 & $46, X Y$ & N.A. & N.A. & $(-)$ & N.A. & N.A. & N.A. & N.A \\
\hline 3 & $46, \mathrm{XX}$ & N.A. & $(-)$ & $(-)$ & $(-) \mathrm{F} 3 / \mathrm{H} 2$ & $(-)$ & $(-)$ & $(-)$ \\
\hline 4 & ${ }^{*} 2$ & $(-)$ & $(-)$ & N.A. & $(-)$ & $(-)$ & $(-)$ & $(-)$ \\
\hline 5 & ${ }^{*} 3$ & $(-)$ & $(-)$ & N.A. & $(-)$ & $(-)$ & $(-)$ & $(-)$ \\
\hline 6 & $46, X Y$ & N.A. & N.A. & N.A. & N.A. & N.A. & N.A. & N.A. \\
\hline \multicolumn{9}{|c|}{ Results of G-band } \\
\hline${ }^{*} 1$ & \multicolumn{8}{|c|}{$74, \mathrm{XXY},+3,+5,+6$, add $(6)(\mathrm{q} 13) \times 2,+7,+8,+9,+10,+12,-13,+15,-18,-21,-22$} \\
\hline *2 & \multicolumn{8}{|c|}{ 46, XY, add (3)(p21), add (6)(q13), } \\
\hline & \multicolumn{8}{|c|}{ 46, idem, del (7)(q32) } \\
\hline & \multicolumn{8}{|c|}{ 46, idem, del (7)(q?) } \\
\hline *3 & \multicolumn{8}{|c|}{$46, \mathrm{XX}$, add $(8)(\mathrm{p} 11.2)$} \\
\hline
\end{tabular}

FISH: fluorescense in situ hybridization; B: Bcl2; H: IgH; F: FGFR3; M: MYC; C: centromere.

the del17p probe set. Furthermore, three signals of FGFR3 in cases 1 and 3, three signals of $\mathrm{IgH}$, and three signals of cyclin D1 in case 1 were obtained.

\subsection{Responses and Survival}

As the initial therapy, R-CHOP, cladribine, and alkylating-agent-based regimens were used in 3,1 , and 1 symptomatic patients, respectively. One of the 5 patients achieved VGPR, 3 achieved PR, and 1 did not respond to treatment. One did not receive any treatment because of the poor PS and pneumonia. At a median follow-up duration of 527 days, 4 patients were alive and 2 had died as a result of disease progression.

\section{Discussion}

WM has been recognized as an indolent B-cell lymphoma in the WHO classification [1]. It is noted that IgM myeloma [32,33] and marginal zone B-cell lymphoma with plasmacytic cell differentiation [7] are sometimes difficult to differentiate to WM; therefore, clinical, pathological, FCM, and cytogenetic aberrations data are essential to make a precise diagnosis. Many reports have suggested that WM sometimes comprises $15 \%-30 \%$ of lymphadenopathy, and sometimes affects the liver, spleen, and other sites [1,2,6-8].One of the unique findings of the present study involves the results of clinical and radiological features. In the present study, four out of the 6 cases showed invasion in the post-peritoneum on CT scan (Figure 1(a)), and interestingly, the pattern of invasion more appropriately represented a soft tissue mass rather than lymphadenopathy. Furthermore, 1 patient had bone lesions and 1 had an extra-medullary mass. These results suggested relatively higher invasion sites other than bone marrow, and this might be one of the features of WM in Japan. Banwait et al. reported the role of whole-body positron emission tomography (PET) with fluorine-18-fluorodeoxyglucose imaging in WM and its contribution to detecting the involved sites. In the near future, the PET/CT scan might be combined to estimate the distribution of WM at diagnosis and for response assessment [8].

There are relatively few reports of FCM analysis and IHC studies with WM, and the results have been controversial so far [2,13-16]. In the present study, FCM analysis showed that all patients were positive for CD45, CD19, CD20, and CD38, while 2 were positive for CD56. All patients were negative for CD10. By IHC studies, 4 out of 4 patients were positive for CD45, CD20, CD79a, and CD138. In the recent review from the Dana Farber Cancer Institute, they mentioned that neoplastic cells were thought to be B-cell arrested after somatic hyper-mutation in the germinal center, before terminal differentiation to plasma cells; thus, the neoplastic cells expressed pan-B marker and lacked CD38 [2]. On the other hand, Howard et al. reported a comparison of IHC with 6-color FCM in WM $[15,16]$. They reported that neoplastic cells in WM expressed both CD19 and CD45, whereas primary plasma cell neoplasms were CD19- or CD45-negative by FCM parallel to IHC; furthermore, co-expression of CD38 and CD138 was noted in 4 out of the 8 cases in WM by FCM [16]. Thus, our cases in the 


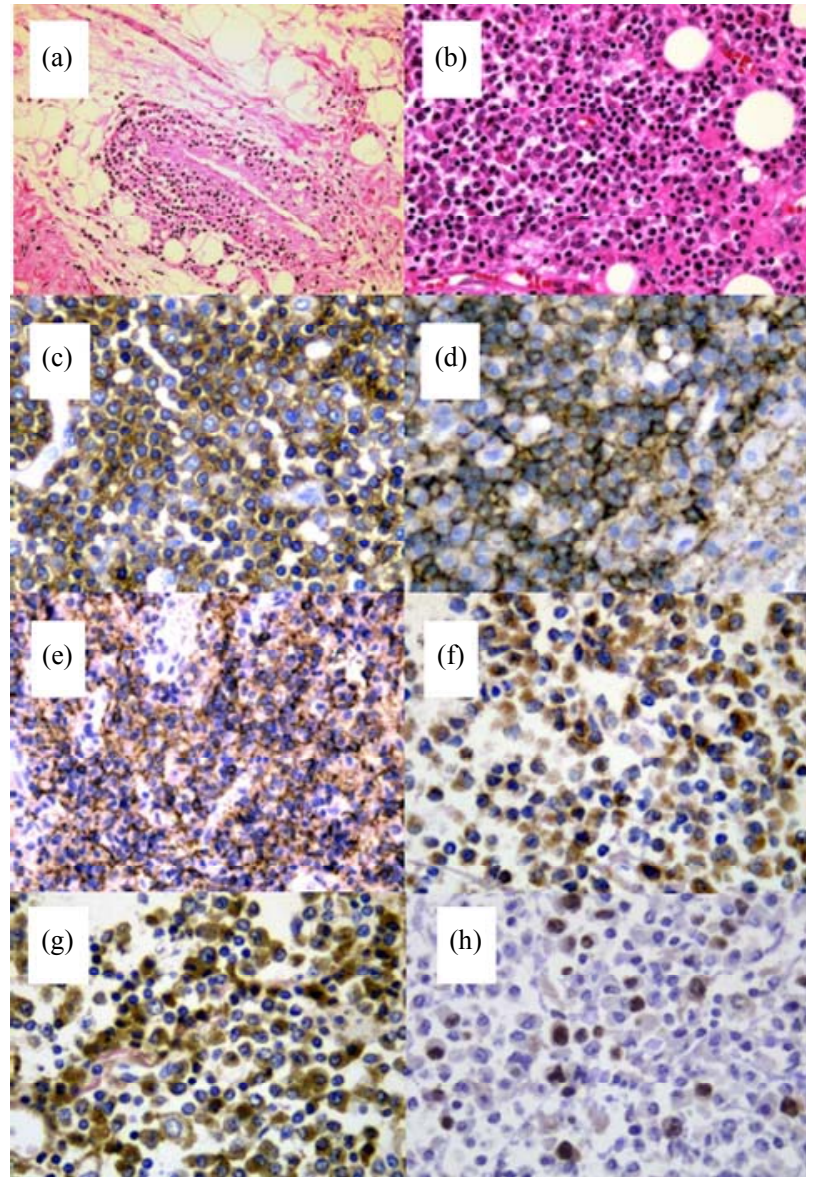

Figure 2. Neoplastic cells in autopsied specimens of case 4. (a) Diffuse invasion of neoplastic cells was identified in the extramedullary mass (hematoxylin and eosin staining, original magnification $\times 200$ ); (b) Neoplastic cells from the soft tissue mass in the retro-peritoneum (hematoxylin and eosin staining, original magnification $\times 400$ ); (c) Staining with CD45 (original magnification $\times 630$ ); (d) CD20 staining. The membrane of neoplastic cells was strongly positive (original magnification $\times 630$ ); (e) Staining with CD138. The cytoplasm of neoplastic cells was strongly positive (original magnification $\times 400$ ); (f) Staining with immunoglobulin $M$ Staining. The cytoplasm of neoplastic cells was positive (original magnification $\times 630$ ); (g) Immunoglobulin lambda staining. Neoplastic cells were positive (original magnification $\times 630$ ); (h) Staining with Ki-67. Stained mainly in the large nuclei (original magnification $\times 630$ ).

present study were considered to be compatible with WM, although the ratio of expression of both CD38 and CD138 was extremely high in our cases, and it is emphasized that 2 out of 6 cases were positive for CD56.

The most common cytogenetic abnormality identified in patients with WM has been reported to be deletion of the long arm of chromosome 6 , which is seen in $40 \%$ $55 \%$ of cases and is associated with poor prognosis features such as high beta2-MG, elevated M-protein, and a greater tendency to display anemia and hypoalbumine- mia $[1,2,17,18]$. Other cytogenetic abnormalities, including trisomy 4 , trisomy 5 , monosomy 8 , and deletion $20 \mathrm{q}$, and lacked $\mathrm{IgH}$ rearrangement $[1,2,17,19,24]$, have been reported as common cytogenetic aberrations. Focusing on the long arm of chromosome 6, tumor suppressor genes, PRDM1 gene and TNFAIP3, are located in 6q. Interestingly, case 1 showed an additional 6q, although no cases showed del6q in the present study. Bang et al. reported that 3 out of 29 cases of WM had del6q by FISH analysis in a Korean multicenter study [25], and Shuhua also reported a lower incidence of del6q in a Chinese retrospective study [27], and these results were consistent with our results that the incidence of del6q might be lower in East Asia than US and Europe. Furthermore, abnormalities of add (8)(p11.2) in case $5[34,35]$ and add (3)(p21), add (6)(q13) [36,37] in case 4 were detected by the G-band method in the present study, which have also been reported in multiple myeloma and plasma cell leukemia cases in the present study. On FISH analysis, case 1 showed additional chromosomes of 8 and 17, and three signals of FGFR3 were recognized in cases 1 and 3 in the present study. Recently, Azab et al. reported that the cell line of WM exhibited FGFR3 overexpression in FISH, FCM, and IHC studies; furthermore, Dovitinib, an inhibitor of FGFR3, successfully decreased cell survival, increased apoptosis, and induced cell cycle arrest [20].

In summary, although the present retrospective study was performed at a single Japanese institution with limited WM cases, the results suggest that WM in Japanese cases might be heterogeneous and considered to have disease manifestation of both myeloma and B-cell lymphoma; a high incidence of invasion sites other than bone marrow, higher co-expression of CD38 and CD138 in neoplastic cells, and lack of del6q and detection of cytogenetic aberrations, which have been reported in plasma cell neoplasm. Further large studies are warranted.

\section{REFERENCES}

[1] S. H. Swerdlow, F. Berger and S. A. Pikeru, "Lymphoplasmacytic Lymphoma," In: S. H. Swerdlow, E. Campo, N. L. Harrus, et al., World Health Organization Classification of Tumour of Hematopoietic and Lymphoid Tissues, IARC Press, Lyon, 2007, pp. 194-195.

[2] G. C. Issa, H. Leblebjian and A. M. Roccaro, "New Insights into the Pathogenesis and Treatment of Waldenstrom Macroglobulinemia," Current Opinion in Hematology, Vol. 18, No. 4, 2011, pp. 260-265. doi:10.1097/MOH.0b013e3283474e5b

[3] M. A. Gertz, "Waldenström Macroglobulinemia: 2011 Update on Diagnosis, Risk Stratification, and Management," American Journal of Hematology, Vol. 86, No. 5, 2011, pp. 411-416. doi:10.1002/ajh.22014 
[4] A. Vijay and M. A. Gertez, "Waldenström Macroglobulinemia," Blood, Vol. 109, No. 12, 2007, pp. 5096-5130. doi:10.1182/blood-2006-11-055012

[5] Lymphoma Study Group of Japanese Pathologists, "The World Health Organization Classification of Malignant Lymphomas in Japan: Incidence of Recently Recognized Entities," Pathology International, Vol. 50, No. 9, 2000, pp. 696-702. doi:10.1046/j.1440-1827.2000.01108.x

[6] M. A. Dimopoulos and A. Anagnostopoulos, "Waldenström's Macroglobulinemia," Best Practice and Research Clinical Haematology, Vol. 18, No. 4 ,2005, pp. 747-765. doi:10.1016/j.beha.2005.01.028

[7] R. L. Sargent, J. R. Cook and N. I. Aguilera, "Fluorescence Immunophenotypic and Interphase Cytogenetic Characterization of Nodal Lymphoplasmacytic Lymphoma," American Journal of Surgical Pathology, Vol. 32, No. 11, 2008, pp. 1643-1653. doi:10.1097/PAS.0b013e3181758806

[8] R. Banwait, O. Regan and F. Campigotto, "The Role of ${ }^{18}$ F-FDG PET/CT Imaging in Waldenstrom Macroglobulinemia," American Journal of Hematology, Vol. 86, No. 7, 2011, pp. 567-572. doi:10.1002/ajh.22044

[9] A. Chiappella, C. Ciochetto and L. Orsucci, "Update in Indolent Non-Hodgkin Lymphoma (NHL): Paradigm for Waldenström's Macroglobulinemia (WM)," Clin Lymphoma Myeloma Leuk, Vol. 11, No. 1, 2011, pp. 149-151. doi:10.3816/CLML.2011.n.035

[10] L. Ioakimidis, C. J. Patterson and Z. R. Hunter, "Comparative Outcomes Following CP-R, CVP-R, and CHOP$\mathrm{R}$ in Waldenström's Macroglobulinemia," Clinical Lymphoma, Myeloma, Vol. 9, No. 1, 2009, pp. 62-66. doi:10.3816/CLM.2009.n.016

[11] C. Buske, E. Hoster and M. Dreyling, "German LowGrade Lymphoma Study Group. The Addition of Rituximab to Front-Line Therapy with CHOP (R-CHOP) Results in a Higher Response Rate and Longer Time to Treatment Failure in Patients with Lymphoplasmacytic Lymphoma: Results of a Randomized Trial of the German Low-Grade Lymphoma Study Group (GLSG)," Leukemia, Vol. 23, No. 1, 2009, pp. 153-161. doi:10.1038/leu.2008.261

[12] S. P. Treon, C. Hanzis and C. Tripsas, "Bendamustine Therapy in Patients with Relapsed or Refractory Waldenström's Macroglobulinemia," Clinical Lymphoma, Myeloma, and Leukemia, Vol. 11, No. 1, 2011, pp. 133-135. doi:10.3816/CLML.2011.n.030

[13] R. G. Owen, S. P. Treon and A. Al-Katib, "Clinicopathological Definition of Waldenstrom's Macroglobulinemia: Consensus Panel Recommendations from the Second International Workshop on Waldenstrom's Macroglobulinemia," Seminers in Oncology, Vol. 30, No. 2, 2003, pp. 110-115.

[14] E. D. Remstein, C. A. Hanson and R. A. Kyle, J. M. Hodnefield and P. J. Kurtinet, "Despite Apparent Morphologic and Immunophenotypic Heterogeneity, Waldenstrom's Macroglobulinemia Is Consistently Composed of Cells along a Morphologic Continuum of Small Lymphocytes, Plasmacytoid Lymphocytes, and Plasma Cells,"
Seminers in Oncology,Vol. 30, No. 2, 2003, pp. 182-186. doi:10.1053/sonc.2003.50073

[15] P. J. Kurtin, K. S. Hobday and S. Ziesmer, "Demonstration of Distinct Antigenic Profiles of Small B-Cell Lymphomas by Paraffin Section Immunohistochemistry," American Journal of Clinical Pathology, Vol. 112, No. 3, 1999, pp. 319-329.

[16] M. T. Howard, J. Hodnefield and W. G. Morice, "Immunohistochemical Phenotyping of Plasma Cells in Lymphoplasmacytic Lymphoma/Waldenström's Macroglobulinemia Is Comparable to Flow Cytometric Techniques,' Clinical Lymphoma, Myeloma, and Leukemia, Vol. 11, No. 1, 2011, pp. 96-98. doi:10.3816/CLML.2011.n.018

[17] R. F. Schop, W. M. Kuehl and S. A. V. Wier, "Waldenström Macroglobulinemia Neoplastic Cells Lack Immunoglobulin Heavy Chain Locus Translocations but Have Frequent 6q Deletions," Blood, Vol. 100, No. 8, 2002, pp. 2996-3001. doi:10.1182/blood.V100.8.2996

[18] E. Braggio, J. J. Keats and X. Leleu, "High-Resolution Genomic Analysis in Waldenström's Macroglobulinemia Identifies Disease-Specific and Common Abnormalities with Marginal Zone Lymphomas," Clinical Lymphoma and Myeloma, Vol. 9, No. 1, 2009, pp. 39-42. doi:10.3816/CLM.2009.n.009

[19] R. F. Schop, S. M. Jalal and S. A. V. Wier, "Deletions of 17 p13.1 and 13 q14 Are Uncommon in Waldenström Macroglobulinemia Clonal Cells and Mostly Seen at the Time of Disease Progression," Cancer Genetics and Cytogenetics, Vol. 132, No. 1, 2002, pp. 55-60. doi:10.1016/S0165-4608(01)00526-X

[20] A. K. Azab, F. Azab and P. Quang, "FGFR3 Is Overexpressed Waldenström Macroglobulinemia and Its Inhibition by Dovitinib Induces Apoptosis and Overcomes Stroma-Induced Proliferation," Clinical Cancer Research, Vol. 17, No. 13, 2011, pp. 4389-4399. doi:10.1158/1078-0432.CCR-10-2772

[21] W. J. Chng, R. Schop and T. Price-Troska, "Gene Expression Profiling of Waldenstrom's Macroglobulinemia Reveals a Phenotype More Similar to Chronic Lymphocytic Leukemia than Multiple Myeloma," Blood, Vol. 108 , No. 8, 2006, pp. 2755-2763. doi:10.1182/blood-2006-02-005488

[22] N. C. Gutierrez, E. M. Ocio and J. D. L. Rivas, "Gene Expression Profiling of B Lymphocytes and Plasma Cells from Waldenstrom's Macroglobulinemia: Comparison with Expression Patterns of the Same Cell Counterparts from Chronic Lymphocytic Leukemia, Multiple Myeloma and Normal Individuals," Leukemia, Vol. 21, No. 3, 2007, pp. 541-549. doi:10.1038/sj.leu.2404520

[23] Y. Liu, K. Miyazawa and G. Sashida, "Deletion (20q) as the Sole Abnormality in Waldenström Macroglobulinemia Suggests Distinct Pathogenesis of 20q11 Anomaly," Cancer Genetics and Cytogenetics, Vol. 169, No. 1, 2006, pp. 69-72. doi:10.1016/j.cancergencyto.2006.03.013

[24] N. Kawano, N. Ikeda and S. Yoshida, "Successful Treatment of Cryoglobulinemic Glomerulonephritis Derived from Waldenström's Macroglobulinemia by RituximabCHOP and Tandem High-Dose Chemotherapy with Auto- 
logous Peripheral Blood Stem Cell Transplantation," International Journal of Hematology, Vol. 92, No. 2, 2010, pp. 391-397. doi:10.1007/s12185-010-0638-1

[25] S. M. Bang, J. W. Seo and K. U. Park, "Molecular Cytogenetic Analysis of Korean Patients with Waldenström Macroglobulinemia," Cancer Genetics and Cytogenetics, Vol. 197, No. 2, 2010, pp. 117-121. doi:10.1016/j.cancergencyto.2009.11.008

[26] Y. M. Won, S. J. Kim and K. Kim, "Clinical Features and Treatment Outcomes of Lymphoplasmacytic Lymphoma: A Single Center Experience in Korea," Annals of Hematology, Vol. 89, No. 10, 2010, pp. 1011-1018. doi:10.1007/s00277-010-0978-1

[27] Y. Shuhua, C. Lui and L. Zengjun, "Distinct Characteristics of Chinese Patient with Waldenstrom Macroglobuminemia: A Report with 90 Cases from a Single Representative Center," Proceedings of 7th international Workshop on Waldenstrom's Macloglobuminemia, Newport, 26 August 2012.

[28] M. M. Oken, R. H. Creech and D. C. Tormey, "Toxicity and Response Criteria of Eastern Cooperative Oncology Group," American Journal of Clinical Oncology, Vol. 5, No. 6, 1982, pp. 649-655.

doi:10.1097/00000421-198212000-00014

[29] Abbott FISH Technology Protocol, 2012. http://www.abbottmolecular.com/support/fish-tech-suppo rt.html

[30] S. P. Treon, G. Merlini and E. Morra, "Report from the Sixth International Workshop on Waldenstrom's Macroglobulinemia," Clinical Lymphoma, Myeloma, and Leukemia, Vol. 11, No. 1, 2011, pp. 69-73.

[31] P. Morel, A. Duhamel and P. Gobbi, "International
Prognostic Scoring System for Waldenström Macroglobulinemia," Blood, Vol. 113, No. 18, 2009, pp. 41634170. doi:10.1182/blood-2008-08-174961

[32] S. Feyler, S. J. O'Connor and A. C. Rawstron, "IgM Myeloma: A Rare Entity Characterized by a CD20CD56-CD117-Immunophenotype and the $\mathrm{t}(11 ; 14)$," British Journal of Haematology, Vol. 140, No. 5, 2008, pp. 547-551. doi:10.1111/j.1365-2141.2007.06969.x

[33] S. R. Schuster, S. V. Rajkumar and A. Dispenzieri, "IgM Multiple Myeloma: Disease Definition, Prognosis, and Differentiation from Waldenstrom's Macroglobulinemia," American Journal of Hematology, Vol. 85, No. 11, 2010, pp. 853-855. doi:10.1002/ajh.21845

[34] J. R. Sawyer, J. L. Lukacs and N. Munshi, "Identification of New Nonrandom Translocations in Multiple Myeloma with Multicolor Spectral Karyotyping," Blood, Vol. 92, No. 11, 1998, pp. 4269-4278.

[35] R. E. Tiedemann, N. Gonzalez-Paz and R. A. Kyle, "Genetic Aberrations and Survival in Plasma Cell Leukemia," Leukemia, Vol. 22, No. 5, 2008, pp. 1044-1052. doi:10.1038/leu.2008.4

[36] N. V. Smadja, D. Leroux and J. Soulier, "Further Cytogenetic Characterization of Multiple Myeloma Confirms That 14q32 Translocations Are a Very Rare Event in Hyperdiploid Cases," Genes, Chromosomes \& Cancer, Vol. 38, No. 3, 2003, pp. 234-239. doi: $10.1002 /$ gcc. 10275

[37] A. S. T. Lim, T. J. Chen and T. H. Lim, "Bone Marrow Cytogenetics Workup: Application of Lean Management System to Determine if Additional Cell Workup Is Helpful and Necessary to Analysis," Annals Academy of Medicine Singapore, Vol. 39, No. 9, 2010, pp. 696-704. 